\title{
JUAN CALDERÓN, UN OLVIDADO GRAMÁTICO EN FRAN- CIA E INGLATERRA Su contribución a la enseñanza del español a mediados del siglo XIX
}

\author{
MAR VILAR \\ (Universidad de Murcia)
}

\section{Planteamiento}

Entre los primeros investigadores contemporáneos de la lengua española con criterios científicos y metodología exigente figura por derecho propio Juan Calderón, filólogo que desarrolló su obra en la emigración durante el segundo tercio del siglo XIX.

En su tiempo alcanzó considerable renombre en Inglaterra y Francia (en menor medida en España) como conocedor profundo de la lengua de Cervantes, analista de la misma con original e inimitable estilo y por sus trabajos de proyección didáctica. Sin embargo, su muerte prematura, el que transcurriera casi toda su vida en el extranjero, y el ostracismo perpetuo a que fue condenada en su país de origen su persona, y aún su memoria, por causa de su abandono del catolicismo en tiempos de marcada intolerancia, determinaron la cortina de silencio que se corrió entre nosotros sobre su nombre y su obra. 
De otro lado, fuera de España Calderón ha sido recordado siempre como fundador del periodismo protestante en lengua castellana ${ }^{1}$, controversista acatólico ${ }^{2}$, investigador cervantista ${ }^{3}$ y, sobre todo, como excelso traductor de la Biblia al español ${ }^{4}$, pero no como filólogo, como docente y como renovador de los estudios gramaticales sobre la lengua castellana. Sobre esta dimensión, a nuestro juicio muy digna de ser destacada en la obra del ilustre polígrafo español, y quien bien merecería ser estudiada in extenso, incide esta primera, y casi telegráfica, aproximación al tema.

\section{Un profesor de lengua española en el exilio}

Menéndez Pelayo fue el primero en atraer la atención sobre Calderón treinta años después de su muerte, cuando el nombre de éste se hallaba absolutamente olvidado entre sus paisanos, para incluirle en su catálogo de heterodoxos, pero también, y sobre todo, para reivindicarle como maestro del idioma. «Fuera de Blanco White y de Usoz - refiere - el único protestante español digno de memoria entre los de este siglo, y no ciertamente por lo original y peregrino de sus errores religiosos, sino por la importancia que le dieron sus méritos de filólogo y humanista, y la docta pureza con que mánejaba la lengua castellana, es D. Juan Calderón, apóstata de la Orden de San Francisco».

Calderón había nacido en Villafranca de los Caballeros, no lejos de Alcázar de San Juan, en 1791, siendo hijo del médico local. Habiendo entrado en la Orden franciscana, se formó en los conventos de Lorca y Alcázar, pertenecientes a la Provincia Observante de Cartagena. En ellos estudiaría humanidades, filosofía y teología. La Guerra de la Independencia, como en tantos otros casos, le impuso una exclaustración temporal de seis años, durante los cuales leyó a los

Mar VILAR, «El nacimiento de la Prensa protestante en lengua española. El Dr. Juan Calderón y sus revistas londinenses Catolicismo Neto y El Examen Libre», Actas de las Jornadas sobre Prensa y Sociedad en la España Contemporánea. Murcia. Publicaciones de la Universidad. 1995, ps. 107-148

2 Juan Bta. VILAR, «El filólogo, helenista y reformador religioso Juan Calderón en la emigración liberal de 1823-1833», Homenaje a Miguel Artola. Madrid. Alianza Editorial. 1995, t.III.

3 M. VILAR, «Un manuscrito cervantista rescatado en Inglaterra para su publicación en España en 1854. El Cervantes vindicado del Dr. Juan Calderón», Bulletin Hispanique, t.96, $\mathrm{n}^{\circ} 2$ (juillet-déc. 1994), 417-433.

$4 \quad$ J.B. VILAR; M. VILAR, «Juan Calderón, traductor de la Biblia al español en la Inglaterra victoriana», Diálogo Ecuménico, XXX, n 96 (1995), ps. 7-30.

5 Marcelino MENENDEZ PELAYO, Historia de los Heterodoxos Españoles. Madrid. B.A.C. 1956, t.II, ps. 1029-1030.6 [Juan CALDERóN,] Don Juan Calderón. [Prólogo de Luis Usoz y Río.]. [Madrid]. [¿Imp. J. Martín Alegría?]. Año 1855, XI-63 ps. (en $8^{\circ}$ ). De esta autobiografía fue publicada traducción francesa con algunas adiciones por J. Nogaret: [J. CALDERON,]. Don Juan Calderón. Sa vie écrite par lui-mềme, suivie de courtesnotices sur quatre chrétiens Espagnols et sur l'evangelisation de l'Espagne. París. J. Bonhoure et Cie, Editeurs. 1880, 71 ps. 
empiristas británicos y a los enciclopedistas franceses. De regreso en su convento en 1814, concluyó sus estudios, hizo sus votos perpetuos, se ordenó sacerdote y fue designado profesor de filosofía en el convento de Alcázar.

El bisoño y un tanto descreído profesor no tardó en tener problemas por causa de las opiniones religiosas de dudosa ortodoxia que divulgaba en las aulas. Afortunadamente para él la revolución de 1820 facilitó su salida del claustro para convertirse en sacerdote secular. Como tal ejerció hasta que el fracaso de la efímera experiencia constitucionalista le obligó a abandonar el país en 1823, al ser denunciado como notorio clérigo liberal.

Nuestro emigrado explica en una autobiografía publicada por sus amigos después de su muerte ${ }^{6}$, los detalles de su tormentosa andadura en el exilio. Su conversión al protestantismo en Bayona, su matrimonio en Burdeos, su ordenación en Londres en 1830 como ministro anglicano, y las grandes dificultades y privaciones que hubo de afrontar para salir adelante con su familia. Entre otras ocupaciones, fue profesor de español, latín y griego, corrector de galeradas, copista de manuscritos en la British Library, traductor, agente distribuidor de biblias y folletos al servicio de asociaciones protestantes, periodista y redactor de tratados de controversia religiosa. Con frecuencia hubo de ocuparse también en diversos trabajos mecánicos para completar unos ingresos de mera subsistencia.

El fracaso de su estancia en España entre 1842 y 1844 , al amparo de una fugaz liberalización del régimen español en sentido progresista, le obligó a regresar a Francia. Un año después (1845) fijó definitivamente su residencia en Inglaterra. Aquí fue protegido desde Madrid por el bibliófilo y filántropo don Luis Usoz y Río, y por el colaborador inglés de éste, el hispanista Benjamín B. Wiffen, quienes asociaron al emigrado a la empresa de editar una Colección de Reformistas Antiguos Españoles, los clásicos olvidados del protestantismo español del siglo XVI (veintiún volúmenes aparecidos entre 1847 y 1865 en Londres, Madrid y San Sebastián).

Tal circunstancia, así como la contratación de Calderón como profesor de lengua y civilización españolas en el King's College de Londres, aseguraron al emigrado los recursos necesarios para sobrevivir, y mayor tiempo para sus empeños literarios. Así transcurría el tiempo hasta que le visitó la muerte en su casa de Londres en 29 de enero de 1854, cuando contaba 63 años de edad.

- [Juan CALDERÓN,] Don Juan Calderón. [Prólogo de Luis Usoz y Río.]. [Madrid]. [¿Imp. J. Martín Alegría?]. Año 1855 , XI-63 ps. (en $8^{\circ}$ ). De esta autobiografía fue publicada traducción francesa con algunas adiciones por J. Nogaret: [J. CALDERÓN,]. Don Juan Calderón. Sa vie écrite par lui-même, suivie de courtes notices sur quatre chrétiens Espagnols et sur l'evangelisation de l'Espagne. París. J. Bonhoure et Cie, Editeurs. 1880, 7 l ps.7 Un detallado y actualizado repertorio de estos docentes de la lengua española dentro y fuera de España, así como de sus actividades y aportaciones (gramáticas, vocabularios, diccionarios y demás material didáctico) puede verse en: Aquilino SÁNCHEZ PÉREZ, Historia de la enseñanza del español como lengua extranjera. Madrid. Sociedad General de Librería. 1992. 


\section{Primeros empeños filológicos}

La inclinación de Juan Calderón por el estudio e investigación de la lengua española, como en el caso de tantos otros emigrados en la época por motivos políticos, le fue impuesta por la necesidad. Siendo hombre de letras, con una sólida formación en los clásicos grecolatinos, con numerosas lecturas de autores españoles y extranjeros, y además experto cervantista, no tuvo gran dificultad en convertirse en profesor de lengua y literatura españolas, primero en Francia y luego en Inglaterra.

Pero a diferencia de la mayoría de sus correligionarios ocupados en este menester como actividad meramente coyuntural para sobrevivir, Calderón pertenece al corto y selecto número de quienes hicieron de ese oficio una profesión estable, y en algún caso también un arte. Entre éstos Vicente Salvá, Emmanuel del Mar, Bonifacio Sotos Ochando, M.E. Nuñez de Taboada o Mariano Velázquez de la Cadena, por mencionar varios entre los más repre- sentativos ${ }^{7}$. Todos ellos, coetáneos de Calderón, y como éste a un tiempo emigrados políticos (en Francia, Gran Bretaña y los Estados Unidos) y conocedores en diverso grado del idioma español y de las técnicas para su enseñanza como lengua extranjera tanto en Europa como en la América anglófona.

Calderón recogió el fruto de sus lecturas, y las experiencias y observaciones cosechadas en sus clases de castellano en diferentes centros privados y en su propio domicilio durante los tres primeros lustros de su emigración, en dos volúmenes misceláneos que, con el título de Revue Grammaticale de la Langue Espagnole ${ }^{8}$ apareció en Burdeos en 1838-1839. De esta publicación trataré después al referirme a la traducción castellana de la misma publicada en Madrid en 1843.

Acaso sea también del filólogo de la Mancha una cartilla de aprendizaje de la lengua de Cervantes o Ejercicios de lectura para las personas que se dedican a aprender el español ${ }^{9}$, obrita presentada de forma anónima, publicada en $12^{\circ}$ en Burdeos y en 1841 en la imprenta de Sewerinck. Fue hecha una tirada de 500 ejemplares, la fecha del depósito es del mes de junio (en el precedente enero Calderón depositó en el mismo lugar un tratadito de controversia religiosa ${ }^{10}$ ), y aparece como depositario cierto Enrich.

7 Un detallado y actualizado repertorio de estos docentes de la lengua española dentro y fuera de España, así como de sus actividades y aportaciones (gramáticas, vocabularios, diccionarios y demás material didáctico) puede verse en: Aquilino SÁNCHEZ PÉREZ, Historia de la enseñanza del español como lengua extranjera. Madrid. Sociedad General de Librería. 1992

\& [J.]. CALDERÓN, Revue Granmaticale de la Langue Espagnole. Par M. ... Bordeaux. De. Mons. 1838-1839, 2 vols. (en $8^{\circ}$ ).

$9 \quad$ Burdeos. Imp. Sewerinck. 1841 (en $12^{\circ}$ ).

10 J. CALDERÓN, Respuesta de un español emigrado a la carta del Padre Areso, por D. (...). Bordeaux. Imprimiérie de E. Mons, rue Sautegron, 14. (1841), 8 ps. (en $8^{\circ}$ ). 
Este último dato induce a Nuñez de Arenas a señalar a Enrich como autor de la obra ${ }^{11}$, si bien no falta quien sugiera ${ }^{12}$ que por haberse ausentado Calderón de Burdeos por esas fechas, acaso el tal Enrich, a su vez español emigrado, quedase comisionado por aquel para vigilar la edición del opúsculo. Pero también pudo tratarse de un encargo a alguno de los numerosos plumíferos españoles que vivían en Burdeos a la sombra del entonces pujante negocio editorial de esa ciudad. Encargo realizado por la imprenta Sewerinck o por algún otro de los editores y exportadores bordeleses de libros en castellano, que cubrían la demanda francesa, pero sobre todo que encaminaban sus productos al mercado suramericano y de forma clandestina a la propia España.

Sea como fuere, la Revue Grammaticale editada por Calderón, y los mencionados Ejercicios de lectura se insertan en toda una tradición publicística sobre la lengua española y su aprendizaje, que en Francia se remonta cuando menos a la segunda mitad del siglo XVI, con los trabajos, entre otros, de Antonio del Corro. Era éste un monje jerónimo sevillano, converso al protestantismo, y destacado humanista, quien en la época en que permaneció en la pequeña corte del Bearn fue preceptor del futuro Enrique IV de Francia, a quien enseñó castellano y para quien escribió una gramática publicada luego en Oxford, año 1586. Al parecer ${ }^{13}$, de ella circuló también en Francia una edición parisina del mismo año, acaso la misma inglesa con falsa portada.

En la propia Burdeos no faltaban precedentes a los dos volúmenes de estudios gramaticales publicados por Calderón en esa ciudad. Que sepamos, el ejemplo más inmediato Le nouveau Sobrino, ou Grammaire de la Langue Espagnole, aparecido en 1818 y de que era autor cierto Francisco Martínez ${ }^{14}$. No parece tratarse de Francisco Martínez de la Rosa, el célebre político y literato, a la sazón recluido por sus ideas liberales en los presidios de Africa, donde permanecería hasta 1820 , si bien después del 23 publicaría varios estudios gramaticales y libritos de lectura para la niñez y juventud, algunos de los cuales fueron editados en Francia.

Es probable que Juan Calderón manejase la gramática de Martínez de 1818, así como obras similares publicadas en París y Londres en el mismo año sobre igual temática. Entre las editadas en francés a partir del expresado año, las de G.

"Manuel NÚN NEEZ ARENAS, «Impresos españoles publicados en Bur-deos desde 1850 », Revue Hispanique, LXXXI (1993), p.492.

12 Véase nota 1 supra.

13 Antonio del CORRO, Reglas gramaticales para aprender la lengua española y francesa. confiriendo la una con la otra según el orden de las partes de la oración. Oxford. John Barnes. 1586. Se ha hablado (C. LÓPEZ LOZANO, Precedentes de la Iglesia Española Reformada Episcopal. Madrid. IERE. 1991, p. 96) de la existencia, que no he podido verificar, de «... ejemplares idénticos [a los de Oxford] con indicación falsa de ser impresos en París».

14 Francisco MARTÍNEZ, Le nouveau Sobrino, ou Grammaire de la Langue Espagnole, reduite à 23 leçons. Par (...). Bordeaux. 1818 . 
Hamoniére y F.T.A. Chalimeau de Verneuil, como las de M.E. Nuñez de Taboada, C. Morand y C. Pla y Torres, o la del conocido editor valenciano, a su vez emigrado, Vicente Salvá, aparecidas en París en 1826, 1827 y 1830.

A estas gramáticas, seguirían otras similares, así como vocabularios, guías de conversación, diccionarios... etc., por lo general en francés o bilingües, tales como los tratados publicados por entonces por los ya mencionados Nuñez de Taboada y Hamoniére. O los de F.M. Noriega, P.M.F. Bourgoin, y del prolífico don Bonifacio Sotos Ochando, entre otros. De todos ellos, así como de los mencionados más arriba, da noticia el profesor Aquilino Sánchez en su conocido y muy completo repertorio ${ }^{15}$, que seguimos preferentemente para establecer los antecedentes de los estudios gramaticales de Juan Calderón y las posibles influencias que se dejaron sentir sobre los mismos.

\section{Juan Calderón en España: sus «Diccionario», «Revista» y «Análisis Lógica y Gramatical de la Lengua Española»}

En 1842 Calderón regresó a España, permaneciendo en Madrid por espacio de tres años. Su viaje y estancia fue financiada por diferentes asociaciones evangelistas francesas y británicas, interesadas en difundir los principios de la Reforma en un país conceptuado como uno de los más firmes baluartes de Roma.

El acceso al poder del naciente Partido Progresista con el general Espartero parecía, en efecto, abrir interesantes posibilidades en esa dirección. De hecho así fue, pero Espartero no tardó en caer y la consiguiente reacción conservadora puso punto final a los trabajos del evangelista, desarrollados hasta el momento de forma semiclandestina, escasamente fructíferos y muy contestados en ambientes católicos ${ }^{16}$. Poco después el agente protestante hubo de abandonar el país, ahora para siempre.

Antes de que esto sucediera, y en la medida en que declinaba su desalentador apostolado, Juan Calderón intentó abrirse camino en otro terreno. A tal fin se dio a conocer como gramático y como crítico de la literatura clásica castellana, que conocía como pocos. Esperaba que sus indudables merecimientos tendrían justa recompensa.

Con tales designios frecuentó ambientes cultos de la capital, titulándose «Profesor de Humanidades y Literatura Castellana». En febrero del 43 inició la publicación en Madrid de su Revista Gramatical de la Lengua Española, versión castellana con pequeñas modificaciones de la obra ya mencionada,

is SÁNCHEZ PÉREZ, Historia de la enseñanza del español..., ps. 193-290, 481-489.

16 Sobre la estancia de Calderón en el Madrid de Espartero, véase su autobiografía: [CALDERÓN,] Don Juan Calderón..., p. 54 ss. 
aparecida en Burdeos en 1838-1839. Salía en fascículos mensuales, en $4^{\circ}$ y de extensión variable ${ }^{17}$.

Calderón insistía sobre sus ideas gramaticales expuestas ya un lustro antes en la edición francesa, y que perfilaría mejor en otras dos obras a las que me refiero seguidamente. Al propio tiempo la revista cumplía la función de vulgarizar en España los últimos avances de las investigaciones gramaticales realizadas en Francia sobre la lengua de Cervantes.

Sin embargo la revista tuvo problemas de distribución, sin duda por la reputación de su editor como individuo de dudosa ortodoxia. De forma que se omite el pie de imprenta (ningún impresor quiso comprometerse dando su nombre y las señas de su oficina) y faltan a su vez los datos del librero o libreros, que debían figurar como necesario punto de referencia para el público de cara a la distribución y posibles suscripciones. Estas tareas parece haberlas asumido el propio Calderón, que estampará en portada la dirección de su domicilio en Madrid: «Carrera de San Jerónimo, 43».

Tanto en esta obra, de la que fue a un tiempo editor, director y principal redactor, como en su Diccionario Gramatical de la Lengua Española ${ }^{18}$, aparecido también en Madrid en 1843, y en su libro más conocido -excelente síntesis de 107 páginas- Análisis lógica y gramatical de la Lengua Española ${ }^{19}$, impreso en la misma ciudad en mayo del expresado año, Juan Calderón se da a conocer como lingüista e introductor del método analítico. Desarrolla primero una parte «crítica», en que revisa los desaguisados sufridos a la sazón por el idioma por parte de escritores, periodistas y traductores, seguida de otra «doctrinal», en que aporta sus propias ideas.

Estas se hallaban determinadas por una información lingüística de autodidacta, y por tanto tardía, desigual y en su conjunto poco profunda. Pero la mente clara y cartesiana de Calderón le permitiría llegar a lo esencial sin perderse en los vericuetos del camino.

En su época conventual el antiguo franciscano había adquirido los instrumentos básicos para el dominio del lenguaje en las gramáticas al uso. Acaso durante su primera exclaustración con ocasión de la Guerra de la Independen-

17

MENENDEZ PELAYO -Historia de los Heterodoxos..., II, p. 1.032 erróneamente atribuye a cada cuaderno extensión uniforme de $32 \mathrm{ps}$. En cuanto al número de fascículos publicados, he podido localizar los tres primeros. Dudo que Calderón publicase más. Véase [J. CALDERON,1 Revista Gramatical de la Lengua Española, núms. I (febrero 1843), 16 ps.; 2 (marzo 1843), 40 ps.; 3 (abril 1843), 8 ps. La revista La Luz (28 febrero 1891, p. 20), en la anónima colaboración rotulada «Protestantes españoles modernos. VIII. Juan Calderón», dice sin embargo que llegaron a publicarse siete números de la mencionada revista madrileña del filólogo de la Mancha.

I8 J. CALDERON, Diccionario Gramatical de la Lengua española. (Madrid.) (Carrera de San Gerónimo, ${ }^{\circ}$ 43.) (1843), 48 ps. [publicado como apéndice del Análisis lógica y gramatical...].

10 J. CALDERON, Análisis lógica y gramatical de la Lengua Española. Por Don (...), autor de la Revista Gramatical. Madrid. Carrera de San Gerónimo, nümero 43. Mayo de 1843, 104 ps. (en $\left.8^{\circ}\right)-B 1,12.943$ dd. 2. (1)-. 
cia, entre sus lecturas francesas estuviese Condillac ${ }^{20}$, entonces muy en boga, y omnipresente en toda biblioteca española que se preciase, como lo prueba las testamentarías publicadas ${ }^{21}$ y las causas seguidas por la Inquisición por tenencia de libros prohibidos ${ }^{22}$. En todo caso leyó a éste, y autores afines, después de 1820 , o ya en la emigración.

Ese y otros instrumentos le permitieron profundizar en la lingüística comparada, a lo que sin duda le ayudó su dominio de las lenguas clásicas y de varias modernas. Pero en lo que realmente destacó fue en la aplicación del método analítico, en la disección de las frases y en la indagación de su sentido general y el de los elementos que lo constituyen. Menéndez Pelayo ${ }^{2.3}$ convendría en que el exfranciscano llegó a dominar en su tiempo como nadie el expresado método «... que sabía aplicar magistralmente».

\section{Naturaleza y limitaciones del método de Calderón}

El pensamiento filológico de Calderón es explicitado en el Análisis..., obra que afirma haber escrito a instancias de colaboradores y suscriptores de la Revista Gramatical. Entre ellos no faltaron quienes propusieran seguir en estas cuestiones alguno de los modelos franceses traducidos, si bien Calderón optó por trazar el suyo propio, estimando que «... es necesario hacer uno expresamente para la lengua española, cuya prodigiosa variedad de construcción no puede acomodarse a la estrechez y compasada regularidad de la francesa ${ }^{24}$.

En cuanto al método aludido, Calderón lo expone así ${ }^{25}$ :

20 Abbé de CONDILLAC, Cours d'etude pour l'instruction du Prince de Parme, aujourd' hui Son Altesse Royale l'Infant D. Ferdinand, duc de Parme..., Par M. l'(...). (s.I.) (s.i.) (s.a.).

21 Marcelin DEFOURNEAUX, L'Inquisition espagnole et les livres français au XVIII siécles. París. P.U.F. 1963.

22 Indice General de Libros Prohibidos, compuesto del Indice último de los Libros prohibidos y mandados expurgar hasta fin de diciembre de 1789 por el Señor Inquisidor General y señores del Supreno Consejo de la Santa General Inquisición, de los suplementos del mismo que alcanzan hasia 25 de agosto de 1805, y además de un Index Librorum Prohibitorum iuxta exemplar Romanum Iussu SS.D.N. editum anno MDCCCXXXV; en que van intercalados en sus respectivos lugares los prohibidos hasta fin de 1842. Madrid. Imprenta de D. José Félix Palacios. 1844, p. 91 (El Cours d'etude de Condillac y el Cours de Droit Natural del mismo autor, incluidos en el Indice de la Inquisición española, y vueltos a condenar por la romana por decretos de 22 septiembre 1836 y 9 abril 1842).

2.3 Historia de los Heteredoxos..., II, p. 1032.

24 CALDERÓN, Análisis lógica y gramatical..., p. 3. ¿Es de Calderón un Análisis gramatical y lógica de la lengua francesa, obra publicada en español varios años antes, o bien se trata de un precedente, y acaso, un modelo del tratado filológico del exfranciscano?. En la Gaceta de Madrid de 25 de noviembre de 1830 vemos insertado el siguiente anuncio: «Análisis gramatical y lógica de la lengua francesa, por un amante de la juventud; contiene un breve tratado sobre la construcción: 20 ejercicios de análisis gramatical; y otros 20 ejercicios de análisis lógica. Se vende en la librería de Rodriguez».

25. CALDERÓN, Análisis lógica y granatical..., p. 7. 
«Nuestro plan es muy sencillo, y enteramente analítico. Empezamos a descomponer lo más compuesto, para llegar a los más simples elementos del lenguaje. Analizamos el razonamiento en períodos; descomponemos el período en proposiciones; y descomponemos la proposición en sus partes o elementos inmediatos. Analizamos finalmente cada una de las partes de la proposición en las palabras de que se compone. A esto llamamos análisis gramatical. Damos de todos estos análisis numerosos ejemplos, sacados en su casi totalidad de nuestros más célebres y clásicos escritores».

En realidad las tres obras mencionadas forman parte de un todo. La primera y esencial es el Análisis lógica y gramatical (léase análisis pragmático y morfosintáctico), de la que el Diccionario es un apéndice, hasta el punto de aparecer encuadernado con aquella, aunque con paginación separada, y la Revista un complemento. Calderón sigue por tanto la estructura usual de los manuales de la época que no solían prescindir de varios apéndices o complementos llamados a neutralizar y, en su caso, rescatarles de la excesiva gramaticalidad de su parte inicial.

Sin embargo en el caso que nos ocupa ambos apéndices no cumplen con total satisfacción la función apuntada de forma que la obra en su conjunto no logra variar nuestra impresión de hallarnos ante un tratado de carácter predominantemente normativo. Ello no obstante a que la Revista transcienda los aspectos puramente morfosintácticos, dado que el autor procura no perder nunca el «norte pragmático» del lenguaje, consciente de la necesidad de corregir aquellos errores gramaticales que expongan al texto a alteraciones graves de su sentido original. De este modo sobre el siguiente ejemplo:

«[...] La suscrición al mes cuesta 10 rs. y los que lo estén al Archivo Militar tienen la entrada gratis. Las entradas sueltas cuestan un real, pudiendo verificarlo las veces que se quiera en un día».

hace el autor este comentario:

«Examínese la tercera [claúsula] y se hallará en ella otro lo, que sirve de complemento al verbo verificar. Esto hace que la claúsula por su incorrección diga otra cosa que lo que con ella se quiere decir [...]».

A su vez el dominio de lo teórico subsiste pese a la aportación en el Diccionario de listas de abreviaturas, «dicciones acabadas — por ejemplo- en ulo, ula, imo, ima...», etc., que por su formato nos recuerdan los clásicos listados de palabras agrupados en áreas temáticas, las secciones de diálogos familiares o usuales, u otros materiales de carácter no gramatical.

Puntos esenciales que dan las claves de los principios metodológicos de Calderón, y al propio tiempo de sus limitaciones, son entre otros: el recurso abusivo a prolongadas explicaciones gramaticales, utilización de textos literarios (extractados de los clásicos castellanos) como ejemplos adecuados que 
ilustren puntos gramaticales de interés e introducción de ejercicios gramaticales (con soluciones dadas de antemano por el autor) que sirven más para consolidar la memorización de las reglas y principios ya explicitados que para invitar al alumno a la práctica del idioma.

Por ello las intenciones expuestas por el autor en el prólogo de su obra de trazar un "plan muy sencillo, y enteramente analítico», quedan frustradas por la naturaleza extremadamente prescriptiva y rígida del tratado. Esto es, el autor concibe el poder «guiar a la juventud en el estudio analítico de la lengua castellana», según ha quedado ya subrayado, solamente a través de «descomponer lo más compuesto, para llegar a los más simples elementos del lenguaje». Con este énfasis en diseccionar el discurso en proposiciones («análisis lógica») y en identificar las partes de las mismas, que para él no son sino las clásicas «partes de la oración» («análisis gramatical»), se arriesga a caer en el error de hacer de la gramática un fin en sí misma y de olvidar la verdadera finalidad didáctica del tratado: el lograr la competencia lingüística del alumno.

Para Calderón la que rotula como Análisis lógica es la sección fundamental de su tratado. El autor se sitúa en un nivel pragmático cuando nos define - por ejemplo- el período como aquel pensamiento principal o secundario que «asegura la consecución del fin que se propone el que habla». También desde el punto de vista metodológico entiende que esta parte es necesaria, por cuanto analiza «... el razonamiento o discurso (...) para que entendiendo bien lo que no nos toca como gramáticos, podamos fijar con mayor precisión el punto de donde partimos».

Ofrecemos a continuación la estructura u organización de algunas de las secciones más representativas del Análisis lógica:

- Análisis del período

Arrancando de una definición de lo que es período («pensamiento expresado con los signos del lenguaje»), seguidamente se aporta un ejemplo que se adelante a la explicación gramatical que vendrá después - en este caso un período fragmentado en varias proposiciones numeradas del 1 al $12-$, a continuación el análisis o comentario analítico de dichas proposiciones (relativo al carácter de las mismas y a las relaciones existentes entre ellas), presentación de nuevos principios o reglas gramaticales - que enlacen con lo dicho anteriormente (eg. distinción entre proposiciones incidentes explicativas y determinativas) - ilustrados con un ejemplo o extracto de algún autor clásico y el análisis de ese extracto.

\section{- Ejercicio primero: «para facilitar el análisis»}

Comienza con lo que conceptúa como resumen gramatical de las características, reglas o principios arriba presentados, lo cual es una forma de enlazar, una vez más, el presente punto gramatical con lo dicho anteriormente. Este recurso da mayor consistencia y coherencia al tratado. Sigue la enumeración de excepciones, «casos de dificultad» o irregularidades (elipsis, redundancias), y 
finalmente la presentación de un ejemplo (un período) y un análisis (explicitación de las proposiciones que hay en ese período).

\section{- Proposiciones incidentes}

Esta sección se abre con una serie de definiciones, seguidas de siete principios gramaticales ampliamente explicados y apoyados con ejemplos. La gramática no sólo aparece en el centro del discurso, sino que constituye en sí misma el objeto primordial del aprendizaje. Por tanto Calderón renuncia a que el alumno aprenda la lengua en primer lugar. Relega la práctica lingüística para el final y ofrece además en cada uno de los apartados de ejercicios una solución completa a cada problema.

- Ejercicio segundo

Consta de tres partes: enunciado del ejercicio u objetivo gramatical (relativo al análisis de la construcción); un extracto breve de algún autor clásico y una resolución del ejercicio.

\section{Otras aportaciones. Proyección de la obra de Juan Calderón}

Considerable interés ofrecen sus consejos a los traductores para ser fieles al texto vertido desde una lengua foránea, y al propio tiempo hacerlo en un castellano esmerado y a cubierto de extranjerismos. Tales consejos no eran ociosos en momentos en que cualquier español asilado en el extranjero, por mal que conociera el francés o el inglés, no dudaba en redondear sus ingresos empleándose como traductor por cuenta de las editoriales. «El trabajo a que más generalmente se dedica el emigrado con familia-referiría uno de ellos ${ }^{26}$ - es a dar lecciones de español o a traducir para los libreros que comercian con nuestras antiguas colonias de América: así están inundadas con letras de oro para delicia de las personas de buen humor».

No era el caso desde luego de Calderón, tan versado en la lengua inglesa y francesa como en la suya propia, como bien lo atestiguan sus traducciones desde ambas al español y viceversa ${ }^{27}$.

Por último, Análisis lógica y gramatical de la Lengua española contiene elementos de interés para quienes se interesen por la enseñanza del español como lengua extranjera. Ello en modo alguno debe sorprendernos habida cuenta de que su autor pasó una parte importante de su vida impartiendo clases de español primero en Francia y después en el Reino Unido, para concluir su carrera, según ha quedado apuntado, como profesor de la lengua de Cervantes en el King's College de Londres.

26 Eugenio de OCHOA, «El emigrado», en VV.AA., Costumbristas españoles. Estudio preliminar y selección de textos por E. Correa Calderón. Madrid. Aguilar. 1964, 1, p. 1.039.

27 Referencias a varias de esas traducciones en la autobiografia de Calderón citada cn nota 2 supra, y en nota 8 id. 
A juzgar por los indicios aportados en el Análisis y en las dos obras afines a ésta, y habida cuenta su preferencia por estudios netamente gramaticales, Calderón recurría como docente a una metodología propiamente gramatical, por lo demás a la sazón de uso generalizado, que no conversacional. Ello no supone reproche alguno para el filólogo emigrado, por cuanto aún hoy aquella conserva parte de su vigencia, por más que en nuestro tiempo se dé cada vez mayor prioridad a la utilización de «... materiales lingüísticos extractados de la realidad comunicativa (diálogos, frases...) $)^{28}$, respecto a la gramática y demás instrumentos teóricos.

El texto de Juan Calderón mereció ser recomendado oficialmente para su utilización en centros docentes por Real Orden de 9 de febrero de $1845^{29}$. De la acogida que la obra mereció da fe, aparte la doble edición de 1843 —dentro y fuera de la revista-, reimpresiones posteriores, entre las cuales, dentro todavía de la fase isabelina, conocemos al menos dos. Una segunda edición «corregida y anotada» por don Francisco Merino Ballesteros, publicada en Madrid en $1852^{30}$, y una tercera edición «notablemente mejorada» por el mismo editor y salida de las prensas madrileñas de L.P. Villaverde en $1861^{31}$.

El libro angular de Juan Calderón tuvo una larga descendencia científica, si bien fue obra más utilizada que citada, hecho propiciado por la descalificación político-religiosa de su autor, su exilio y su prematura muerte en el extranjero. Los mejores críticos la tuvieron sin embargo presente, como es el caso de Julio Cejador $^{32}$ o Marcelino Menéndez Pelayo ${ }^{33}$.

Todavía a comienzos del siglo actual, no obstante haber llovido, y aún diluviado, mucho en el vasto y complejo campo de la lingüística desde los tiempos de Calderón, continuaban publicándose «adaptaciones» de su libro, a nombre de otros, incluso en los más apartados parajes de América. Así una

28 SÁNCHEZ PÉREZ, Historia de la enseñanza del español..., p. 2.

2. En una nota manuscrita en francés en el ejemplar cosultado (BNm, U 1.709) se dice lo que sigue: «Par ordenance du 9 Fevrier 1845 S.M. la Reine d'Espagne a prouvé cet ouvrage pour l'enseignement superier de la langue (Voy. la Gácette de ce jour)».

31) J. CALDERón, Análisis lógica y gramatical de la Lengua española. Por D. (...) Segunda edición corregida y anotada por D. Francisco Merino Ballesteros, Inspector General de Instrucción Primaria, Madrid. Imprenta de A. Vicente, calle de Lavapiés, número 10, 1852, 96 ps. (en $8^{\circ}$ ) -raro ejemplar consultado en la B1, 12.942 cc. 5 (2)-.

3 J. CALDERÓN, Análisis lógica y gramatical de la Lengua española. Por D. (...). Tercera edición notablemente mejorada por D. Francisco Merino Ballesteros. Madrid. Librería de D. León Pablo Villaverde, calle de Carretas, núm. 4. 186l, 103 ps. (BNm.).

32 Julio CEJADOR Y FRAUCA, Historia de la Lengua y Literatura castellana. (Comprendidos los autores hispano-americanos). Edición facsímil. Madrid. 1972, p. 377.

33 Véase nota 5 supra. 
Gramática histórica y lógica de la lengua castellana, dada por entonces a las prensas por cierto director del Liceo de la ciudad de Heredia, en Costa Rica.

Al remitir un ejemplar de su libro a Ménéndez Pelayo, el autor centroamericano, muy satisfecho de «... la labor por mí emprendida», y como quien abre nuevos e insospechados territorios a la ciencia, le declararía ufano ${ }^{34}$ : «Vengo creyendo desde hace algún tiempo que es absolutamente indispensable introducir en el estudio de nuestra lengua los resultados de la fililogía comparada, no únicamente desde el punto de vista de la derivación románica, sino también desde un punto de vista superior que nos permita aprovechar las conclusiones más elevadas de la lógica y la psicología lingüísticas».

Una idea que, como tantas otras, había sido no ya anticipada sino formulada en iguales términos por el filólogo de la Mancha sesenta y cuatro años antes. No en vano alguien ${ }^{35}$ ha subrayado que lo que se presenta como «nuevo», con frecuencia no pasa de reacuñación de ideas «viejas», por más que se refundan y vuelvan a perfilar de acuerdo con las exigencias de cada momento.

\section{Conclusiones}

En suma, la contribución de Juan Calderón a la investigación de la lengua española y de su aprendizaje se inserta en ese magno y casi anónimo esfuerzo realizado en un plano privado por quienes en todo tiempo y lugar se han enfrentado con el problema práctico de enseñar un idioma culto como lengua extranjera ${ }^{36}$.

La obra de Calderón como gramático fue escasa pero trascendente y sólida. Aparecida entre 1838 y 1843 , era resultado de veinte años delecturas, estudios y observaciones. Su huella se ha dejado sentir hasta después de 1900.

Es de lamentar que la consideración y estima como gramático ${ }^{37}$ que valicron al filólogo de Alcázar sus publicaciones madrileñas de 1843, no le asegutrasen la deseable estabilidad económica ni le permitieran permanecer en el país. Todavíaresulta más deplorable que, ya en el extranjero, Calderón se viera precisado a abandonar unas investigaciones iniciadas bajo tan alentadores

34 Roberto Brenes Mesén a M. Menéndez Pelayo, Heredia 12 enero 1907, cfr. M. MENÉNDEZ PELAYO, Epistolario. Edición, introducción y notas de M. Revuelta Sañudo. Madrid. Fundación Universitaria Española. 1989, t. XIX, ps. 18-19.

3s SÁNCHEZ PÉREZ, Historia de la enseñanza del español..., p. 2.

36. Aún hoy, como en los días de Calderón, y no obstante el creciente intervencionismo del Estado en estas tareas, la transmisión de un idioma extranjero fundamentalmente «... es un problema de los propios interesados», que no asunto oficial. Véase SÁNCHEZ PÉREZ, op. cit., p. 3.

${ }_{37}$ La solvencia científica de Calderón como filológo no era cuestionada por nadie. Incluso La Esperanza ( 2 julio 1850), detractora temible de aquel como fraile apóstata y hereje, ensalzará sin paliativos sus méritos como gramático. Lo que no pudo por menos de causar la perplejidad de Luis 
auspicios, para probar fortuna como periodista, como traductor, en diferentes empeños literarios y aún como calígrafo, copista y amanuense asalariado.

Discreto poeta - véanse entre otras sus composiciones «Las promesas del Señor» y $\ll$ La Salve del Cristiano ${ }^{38}$ - era mejor prosista ${ }^{39}$, por su estilo sencillo, directo y conciso. Sus contemporáneos le tuvieron ya en la época como filólogo muy culto, de vivo ingenio y excelente estilista ${ }^{40}$.

En cuanto a la posterioridad, bien podemos hacer nuestro el juicio de Menéndez Pelayo ${ }^{41}:$ «No sé si era literato, en todo el rigor de la frase, pero sé que puede calificarse de sutil analizador de los primores del habla castellana, muy frecuentemente versado en la lección de nuestros autores modelos y hábil en desentrañar sus excelencias de pormenor. Era, en suma, un excelente maestro de gramática castellana...».

\author{
ABREVIATURAS UTILIZADAS \\ AWCO: Archivo del Wadham College (Oxford) \\ B1 : British Library (Londres) \\ Sc : Spanish Collection \\ Wp : Wiffen Papers
}

Usoz, a su vez disidente del catolicismo, que preguntaría a Benjamin $B$. Wiffen: $[\ldots]$ «jes jesuita Calderón?, ¿será posible?». El inglés se apresuró a deshacer toda sospecha remitiendo al de Madrid copia manuscrita de unos Diálogos del exfranciscano, tratado de controversia antirromanista, que fue tan del agrado de Usoz que decidió financiar la publicación del opúsculo. "Calderón, según esta obra - apuntará a su corresponsal insular - es cristiano y no jesuita. Mi sospecha fue baja y propia de las circunstancias y personas qe. rodean al qe. en España vive» (AWCO, Sc Wp, Usoz a Wiffen, Madrid, 1848 - sin fecha-).

38 El Examen Libre, 3 (1853), p. 179; 6 (1854), p. 288.

3. «La prosa de J[uan] C[alderón] me parece muy superior a sus versos», referirá Usoz en vida de aquel. AWCO, Sc Wp, Usoz a Wiffen, Madrid 15 julio 1850.

40 Adolfo de CASTRO, Historia de los Protestantes españoles y de su persecución por Felipe II. Obra escrita por (...). Cádiz, 1851, p. 459.

41 Historia de los Heteredoxos..., II, p. 1.032. 